\title{
A forced titration study of the antioxidant and immunomodulatory effects of Ambrotose AO supplement
}

\author{
Stephen P Myers ${ }^{* 1,2}$, Lesley Stevenson 1,5, Phillip A Cheras 1,2, Joan O'Connor 1,2, Lyndon Brooks 2,3, Margaret Rolfe3, \\ Paul Conellan 1,4 and Carol Morris ${ }^{4}$
}

\begin{abstract}
Background: Oxidative stress plays a role in acute and chronic inflammatory disease and antioxidant supplementation has demonstrated beneficial effects in the treatment of these conditions. This study was designed to determine the optimal dose of an antioxidant supplement in healthy volunteers to inform a Phase 3 clinical trial.

Methods: The study was designed as a combined Phase 1 and 2 open label, forced titration dose response study in healthy volunteers $(n=21)$ to determine both acute safety and efficacy. Participants received a dietary supplement in a forced titration over five weeks commencing with a no treatment baseline through 1, 2, 4 and 8 capsules. The primary outcome measurement was ex vivo changes in serum oxygen radical absorbance capacity (ORAC). The secondary outcome measures were undertaken as an exploratory investigation of immune function.
\end{abstract}

Results: A significant increase in antioxidant activity (serum ORAC) was observed between baseline (no capsules) and the highest dose of 8 capsules per day $(p=0.040)$ representing a change of $36.6 \%$. A quadratic function for dose levels was fitted in order to estimate a dose response curve for estimating the optimal dose. The quadratic component of the curve was significant $(p=0.047$ ), with predicted serum ORAC scores increasing from the zero dose to a maximum at a predicted dose of 4.7 capsules per day and decreasing for higher doses. Among the secondary outcome measures, a significant dose effect was observed on phagocytosis of granulocytes, and a significant increase was also observed on Cox 2 expression.

Conclusion: This study suggests that $A m b r o t o s e ~ A O^{\circ}$ capsules appear to be safe and most effective at a dosage of 4 capsules/day. It is important that this study is not over interpreted; it aimed to find an optimal dose to assess the dietary supplement using a more rigorous clinical trial design. The study achieved this aim and demonstrated that the dietary supplement has the potential to increase antioxidant activity. The most significant limitation of this study was that it was open label Phase 1/Phase 2 trial and is subject to potential bias that is reduced with the use of randomization and blinding. To confirm the benefits of this dietary supplement these effects now need to be demonstrated in a Phase 3 randomised controlled trial (RCT).

Trial Registration: Australian and New Zealand Clinical Trials Register: ACTRN12605000258651

\section{Background}

There is now substantial evidence that reactive oxygen species (ROS), or oxygen free radicals, are involved in a range of inflammatory diseases [1-3]. Normally ROS are

\footnotetext{
*Correspondence: smyers@scu.edu.au

${ }^{1}$ Australian Centre for Complementary Medicine Education and Research, A Joint Venture of the University of Queensland and Southern Cross University, Lismore, Australia

Full list of author information is available at the end of the article
}

effectively detoxified in the body by the presence of scavenging substances known as antioxidants and antioxidant defence enzymes. Oxidative stress occurs when there is an imbalance between ROS production and the body's intrinsic scavenging capacity leading to an excess of ROS [3]. Individuals who are critically ill are generally exposed to an increase in oxidative stress [4] which has been demonstrated to be proportional to the severity of their condition [5]. One of the reasons that oxidative stress occurs 
in critical illness, is that the plasma concentrations of antioxidant micronutrients are low. This occurs as a result of fluid losses, low nutrient intakes, dilution of nutrient concentration by resuscitation fluids, and the redistribution of nutrient from plasma to tissues as part of the inflammatory process [6,7].

The low plasma concentration of antioxidant nutrients has led to the postulation that antioxidant therapy may play a role in the treatment of numerous diseases, ranging from acute and chronic inflammation to shock and ischemia/reperfusion injury $[1,2,8,9]$. Recent research using antioxidant therapies has demonstrated positive effects in both acute[10] and chronic inflammatory conditions [11]. A recent review of the role of oxidative stress-related organ dysfunction in inflammatory and septic conditions demonstrated that only three antioxidant nutrients, selenium, glutamine and eicosapentaenoic acid, have demonstrated clinical benefits and reached the highest level of evidence [7]. The reviewers concluded that other antioxidants are still awaiting well-designed clinical trials.

A range of foods have been found to contain antioxidant constituents which have been demonstrated to effect human antioxidant status. These include spinach [12], strawberries [12], honey [13], soy foods [14] and a variety of edible nuts including pistachios [15], almonds [16] and hazelnuts [17]. Phenolic and polyphenolic compounds are responsible for most of the antioxidant capacity found in fruits, vegetables and most botanical antioxidant supplements [18]. These include quercetin a dietary flavonoid (a polyphenolic) abundant in onions [19] and present in a wide variety of fruits and vegetables and the flavonoid epcatechin found in cocoa, tea and grapes [20].

This present study tested a dietary supplement containing a mixture of antioxidant compounds (Vitamin E and quercetin) and concentrated plant extracts (including green tea and grape extracts) using an open label forced titration design to determine both its acute safety and its antioxidant and immunomodulatory effects in a population of healthy smokers and non-smokers. This is a combined Phase 1 and 2 study aimed at determining the optimal dose to assess in a Phase 3 randomized controlled trial.

\section{Methods}

\section{Research Design}

The trial was an open label forced titration dose response study conducted over 5 weeks in healthy smokers and healthy non-smokers in Lismore, a regional city, in northern New South Wales and was conducted in 2005. In a forced titration study, the study preparation at different doses is given to all subjects. In this study the study preparation was given in increasing doses every week over 5 weeks. In order to test the preparation in healthy volun- teers with a low and high exposure to oxidative stress, non-smokers and smokers were selected respectively.

The study was approved by two ethical review panels, the Human Research Ethics Committee of Southern Cross University (Ethics approval number: ECN-04-156) and the University of Queensland Human Research Ethics Committee (Ethics approval number: 200400036). The research was conducted in compliance with Good Clinical Practices (GCP) and in accordance with the guidelines of the Australian National Health and Medicinal Research Council and the Declaration of Helsinki (as revised in 2004). The trial was registered with the Australian and New Zealand Clinical Trials Register (ACTRN12605000258651).

\section{Participants}

A convenience sample healthy individuals, half smokers and half non-smokers, aged between 18 and 50 years were recruited by email from staff and students at Southern Cross University, and from Lismore, and surrounding areas through newspaper advertising, regional radio and television. Individuals were accepted to the study on a first come basis provided they met the study inclusion and exclusion criteria. All participants received a study information sheet outlining the study and signed a consent form agreeing to participate.

A sample size estimate (alpha 0.05 and beta 0.8 ) based on pilot data from an open label study conducted by Mannatech Inc (Coppell, Texas, USA) in healthy nonsmokers required 10 participants to demonstrate changes in the antioxidant status (the primary outcome). In order to assess the effectiveness of the preparation in low and high oxidative stress it was decided to recruit 10 nonsmokers and 10 smokers.

Participants were included if they were healthy, and had neither an acute or chronic medical condition. This was determined by a comprehensive general health questionnaire and assessment by the clinical trial nurse (JO), with any concerns resolved by a medical practitioner (SPM). Baseline bloods were also reviewed to ensure subjects with undiagnosed abnormalities were not included. Participants were excluded if they were: taking antioxidant medications and/or other dietary supplements; if they had poor venous access; if they had a history of any autoimmune disorders or diabetes; if they were taking immune suppressant drugs, cytokines, interferon, Echinacea or other immune stimulating herbs; if they had clinically abnormal liver function tests at baseline; were unwilling to have blood taken 6 times during the study; or were unwilling to comply with the study protocols.

\section{Outcome Measurements}

The primary outcome measurement was ex vivo changes in serum oxygen radical absorbance capacity. The sec- 
ondary outcome measures were in vivo changes in lymphocyte subsets [Mature T Cells (CD3+), B Cells (CD19+), Helper T cells (CD3+CD4+), Cytotoxic T Cells (CD3+CD8+), Natural Killer (NK) Cells (CD3CD16+and/orCD56+)], phagocytosis of granulocytes and monocytes, natural killer cell cytotoxicity and cyclooxygenase-2 (COX-2) expression. These immune indices were chosen to explore other biological activities that may be plausibly altered by components within the preparation under investigation.

Two baseline efficacy measurements were taken one week apart prior to the commencement of study medication and subsequent measurements were taken weekly for 4 weeks. Six measurements were taken in total and participants attended 6 clinics during which weight, blood pressure and concomitant medication use was recorded and fasting blood samples collected.

Safety was assessed by actively monitoring adverse events and by a full blood count, liver function tests and determination of urea, creatinine and electrolytes taken at the first baseline measurement and at the conclusion of the study to assess toxicity to the hemopoietic, hepatic and renal system. Vital signs (pulse and blood pressure) and weight were also monitored at every measurement point.

Subjects returned all remaining capsules at each clinic and these were counted as a measure of compliance. The investigator maintained an inventory record of all capsules received and dispensed. It was assumed that capsules not returned were taken.

\section{Study Supplement and Dosing Schedule}

The study product Ambrotose $\mathrm{AO}^{\circ}$ capsules was provided by Mannatech, Incorporated, (Coppell, Texas). The preparation is sold widely in the United States as a dietary supplement. Each capsule contained $18 \mathrm{mg}$ vitamin $\mathrm{E}$ as mixed tocopherols (as d-alpha, d-beta, d-delta and dgamma tocopherols); $113 \mathrm{mg}$ of an antioxidant blend (quercetin dihydrate; grape skin extract; green tea extract; Terminalia ferdinandiana [Australian bush plum powder], $331 \mathrm{mg}$ of a proprietary blend of plant polysaccharide and fruits and vegetables powders (aloe vera inner leaf gel, gum acacia, xanthan gum, gum tragacanth, gum ghatti, broccoli, brussel sprouts, cabbage, carrot, cauliflower, garlic, kale, onion, tomato, turnip, papaya and pineapple.

The dosing schedule was one capsule daily for one week after completion of the second baseline measurement. At the end of first week of supplementation, participants then commenced on two capsules daily for the second week, followed by 4 capsules daily for the third week and eight capsules daily for the fourth week. Measurements were taken before and after each increase in dosage.

\section{Laboratory Assays}

\section{Serum Oxygen Radical Absorbance Capacity (ORAC)}

The ORAC assay employed in this study measured the antioxidant scavenging capacity of serum samples, against peroxyl radicals induced by 2, 2'-azobis (2-amidinopropane) dihydrochloride (AAPH) (Wako, Richmond, VA, USA) at $37^{\circ} \mathrm{C}$. Fluorescein sodium salt $\left(\mathrm{C}_{20} \mathrm{H}_{12} \mathrm{O}_{5} \cdot 2 \mathrm{Na}\right)$ (Aldrich, St. Louis, MO, USA) was used as the fluorescent probe. The method is based on that of Prior et al. [21] for measuring the antioxidant capacity of plasma and other biological samples.

\section{Sample Preparation}

Serum samples were stored at $-80^{\circ} \mathrm{C}$ until analysis. Samples were thawed to room temperature, mixed by vortex, and then centrifuged ( 3 min. at $13000 \mathrm{~g})$. Serum $(100 \mu \mathrm{L})$ was added to a $1.5 \mathrm{~mL}$ micro centrifuge tube with $300 \mu \mathrm{L}$ Milli-Q water and $400 \mu \mathrm{L} 0.5 \mathrm{M}$ perchloric acid (Sigma, St. Louis, MO, USA), giving a 1 in 8 dilution. Samples were mixed by vortexing, centrifuged ( $5 \mathrm{~min}$. at $13000 \mathrm{~g}$ ), and the supernatant was serially diluted 1 in 2 with 75 mM phosphate buffer, pH7.4 (Sigma, St. Louis, MO, USA), giving a dilution series of 1 in 8,1 in 16,1 in 32 , and 1 in 64. Each dilution was assayed in triplicate.

\section{Method}

Trolox (( \pm )-6-Hydroxy-2,5,7,8-tetra-methylchromane-2carboxylic acid) (Fluka, Buchs, Switzerland), a water soluble analogue of vitamin E, was used as a reference standard. A working Trolox solution $(10 \mu \mathrm{L}$ stock solution, $990 \mu \mathrm{L}$ perchloric acid precipitating solution) was prepared from a Trolox stock solution $(0.01 \mathrm{M}$, in $75 \mathrm{mM}$ phosphate buffer, $\mathrm{pH}$ 7.4). The working solution was then serially diluted 1 in 2 with phosphate buffer $(75 \mathrm{mM}$, pH7.4). A standard curve was established from Trolox standards prepared at $100,50,25$, and $12.5 \mu \mathrm{M}$.

Grape juice (commercially available from supermarket) was included as a control, and was diluted similarly, firstly with perchloric acid precipitating solution, and then serially diluted with phosphate buffer $(75 \mathrm{mM}, \mathrm{pH} 7.4)$, giving final concentrations of $20,10,5$, and $2.5 \mu \mathrm{L} / \mathrm{mL}$.

Briefly, $10 \mu \mathrm{L}$ fluorescein $\left(6.0 \times 10^{-7} \mathrm{M}\right), 20 \mu \mathrm{L}$ samples/ standards/control/blank (perchloric precipitating solution) and $170 \mu \mathrm{L} \mathrm{AAPH}(20 \mathrm{mM})$ were added per well. Immediately after loading, the 96 well black fluorescence plate (Greiner, Frickenhausen, Germany) was transferred to the Wallac Victor2 plate reader, preset to heat to $37^{\circ} \mathrm{C}$, and the fluorescence was measured every minute for 35 minutes. The fluorescence readings were referenced to solvent blank wells. The final serum ORAC values were calculated using linear regression between the Trolox concentration and the net area under the fluorescein decay curve, and were expressed as micromole Trolox equivalents (TE) per litre of serum. 


\section{Lymphocyte Subsets}

Flow cytometric analysis was used for monitoring the expression of CD3+, CD4+, CD8+, CD19+, CD16+ \& CD56+ antigens on peripheral blood lymphocytes (PBL). Staining of PBL was performed by the BD Lyse/No Wash method using MultiTEST IMK kit reagents (BD Biosciences, San Jose, CA, USA).

Briefly, $50 \mu \mathrm{l}$ whole blood (EDTA) was added to $20 \mu \mathrm{l}$ of both monoclonal antibodies (CD3/CD8/CD45/CD4 \& CD3/CD16+56/CD45/CD19). Tubes were vortexed and incubated for 15 minutes in the dark at room temperature. $450 \mu \mathrm{l} 1 \times$ MultiTEST Lysing Solution (BD Biosciences, San Jose, CA, USA). was added to each tube, then tubes were vortexed and incubated for 15 minutes in the dark at room temperature. The samples were then analysed on a BD FACSCalibur flow cytometer, with BD MultiSET software, using excitation wavelengths of $488 \mathrm{~nm} \&$ $635 \mathrm{~nm}$.

Absolute white blood cell (WBC) and lymphocyte percentage values, obtained from a Beckman Coulter AcT Diff analyser, were used for lymphocyte subset calculations.

\section{Phagocytic Activity}

Blood samples were assayed for both granulocyte \& monocyte phagocytic activity (post E. coli stimulation) by flow cytometry using the Phagotest kit (Orpegen Pharma, Heidelberg, Germany).

E. coli, commercially labelled with fluorescein isothiocyanate (FITC) (Orpegen Pharma, Heidelberg, Germany), was added to aliquots of blood from each lithium heparinised blood sample and incubated for 10 minutes at $37^{\circ} \mathrm{C}$. Baseline controls $\left(0^{\circ} \mathrm{C}\right)$ were also run for each sample. For each aliquot, the percentage of phagocytes (granulocytes \& monocytes) that had ingested the FITC labelled bacteria (E. coli) was then determined by flow cytometry using a BD FACSCalibur instrument.

\section{NK Cell Cytotoxic Activity}

Peripheral blood mononuclear cells (PBMC) were prepared from each lithium heparinised blood sample using Ficoll-Paque (Amersham Biosciences, Piscataway, New Jersey, USA). K562 cells, an erythroblastic leukaemia cell line (ATCC, Manassas, VA, USA) susceptible to NK cell cytotoxic activity, were pre-labelled with a green fluorescent dye, DiO (Molecular Probes, Carlsbad, CA, USA). The PBMCs for each sample were incubated for two hours $\left(37^{\circ} \mathrm{C}\right)$ with the $\mathrm{K} 562$ target cells at a ratio of $25: 1$ (PBMC:K562). After incubation, a cell viability dye, propidium iodide (Molecular Probes, Carlsbad, CA, USA), was added to label the K562 target cells permeabilised by NK activity. A target cell control was also run to monitor spontaneous K562 death. The percentage of dead target cells for each sample was determined by flow cytometry using a BD FACSCalibur instrument. Specific NK cell cytotoxicity was determined as the difference between the percent dead $\mathrm{K} 562$ for each test sample and the target cell control. This method is based on that outlined in the NKTest Protocol (Orpegen Pharma).

\section{Cox-2 Expression}

Blood samples were assayed for monocyte Cox-2 expression post stimulation with E. coli lipopolysaccharide (LPS) (Sigma, St. Louis, MO, USA).

LPS (final concentration $0.01 \mu \mathrm{g} / \mathrm{mL}$ ) was added to aliquots of blood from each lithium heparinised blood sample and incubated for two hours at $37^{\circ} \mathrm{C}$. Baseline controls (no LPS) were also run for each sample. Samples from each aliquot were then stained with fluorochrome labelled monoclonal antibodies (mAbs) CD14-PerCP (BD Biosciences, San Jose, CA, USA) then intracellularly with Cox-2-PE (BD Biosciences, San Jose, CA, USA). The percentage of monocytes expressing Cox-2 was then determined by flow cytometry using a Becton Dickinson FACSCalibur instrument. This method is based on that of Ruitenberg and Waters [22].

\section{Results \\ Study Participants}

The study screened 30 individuals by phone resulting in 24 clinic appointments. Subsequently 22 individuals were enrolled in the study. One participant (47 year old male) did not show after week 3 and was lost to follow up. One subject (43 year old female) was withdrawn at week 5 with diarrhoeal complaint, and one subject (37 year old female) was withdrawn at week 6 with an upper respiratory tract infection. Twenty one $(n=21)$ data sets were analysed, comprising 9 non-smokers ( 3 males, 6 females) and 13 smokers ( 5 males, 8 females). The mean age ( \pm SD) of the participants was 41 years $( \pm 8.55)$ with a median age of 43.5 years (range 21 - 50 years). The mean age $( \pm$ SD) of the non-smokers was 42 years $( \pm 7.75)$ with a median age of 44 years (range 27 - 50 years). The mean age $( \pm$ SD) of the smokers was 39.5 years $( \pm 9.58)$ with a median age of 43 years (range 21 - 50 yrs).

\section{Antioxidant Activity}

Descriptive statistics including sample size, mean, standard deviation, minima and maxima for the primary outcome measures of Oxygen Radical Absorption Capacity (serum ORAC) are reported in Table 1 by dosage level, gender and smoking status. Figure 1 graphically represents these finding for serum ORAC by gender and smoking status.

General linear mixed models (SPSS Mixed) with repeated measures were fitted to the data to maximise retention of data on subjects with missed occasions of measurement. Optimal variance-covariance structures (compound symmetry) were fitted to adjust the estimates and their standard errors for the dependency arising from repeated measurements on the same subjects. 
Table 1: Means ( \pm SD), minima and maxima for serum ORAC by gender and smoking status.

\begin{tabular}{|c|c|c|c|c|c|c|c|c|c|c|c|c|}
\hline & & & \multicolumn{5}{|c|}{ Non Smoker } & \multicolumn{5}{|c|}{ Smoker } \\
\hline & & & $\mathbf{N}$ & Mean & SD & Min & Max & $\mathbf{N}$ & Mean & SD & Min & $\operatorname{Max}$ \\
\hline \multirow[t]{18}{*}{ ORAC } & Male & Baseline 1 & 5 & 428 & 115 & 310 & 562 & 3 & 510 & 100 & 439 & 581 \\
\hline & & Baseline 2 & 5 & 391 & 145 & 239 & 577 & 3 & 157 & 42 & 122 & 204 \\
\hline & & Dose 1 & 5 & 389 & 267 & 116 & 728 & 3 & 757 & 145 & 669 & 924 \\
\hline & & Dose 2 & 5 & 397 & 196 & 167 & 645 & 3 & 643 & 89 & 576 & 744 \\
\hline & & Dose 4 & 5 & 649 & 164 & 510 & 885 & 3 & 309 & 183 & 176 & 518 \\
\hline & & Dose 8 & 5 & 536 & 202 & 243 & 707 & 3 & 626 & 38 & 591 & 667 \\
\hline & Female & Baseline 1 & 8 & 352 & 140 & 111 & 535 & 6 & 534 & 65 & 423 & 587 \\
\hline & & Baseline 2 & 8 & 311 & 122 & 135 & 447 & 6 & 287 & 91 & 156 & 429 \\
\hline & & Dose 1 & 8 & 407 & 170 & 71 & 623 & 6 & 460 & 231 & 192 & 849 \\
\hline & & Dose 2 & 8 & 372 & 200 & 122 & 774 & 6 & 396 & 186 & 169 & 626 \\
\hline & & Dose 4 & 8 & 466 & 153 & 263 & 672 & 6 & 460 & 104 & 340 & 615 \\
\hline & & Dose 8 & 8 & 382 & 132 & 169 & 577 & 6 & 292 & 169 & 130 & 499 \\
\hline & All & Baseline 1 & 13 & 380 & 131 & 111 & 562 & 9 & 527 & 68 & 423 & 587 \\
\hline & & Baseline 2 & 13 & 337 & 129 & 135 & 577 & 9 & 244 & 99 & 122 & 429 \\
\hline & & Dose 1 & 13 & 401 & 195 & 71 & 728 & 9 & 559 & 246 & 192 & 924 \\
\hline & & Dose 2 & 13 & 380 & 190 & 122 & 774 & 9 & 478 & 197 & 169 & 744 \\
\hline & & Dose 4 & 13 & 527 & 174 & 263 & 885 & 9 & 410 & 144 & 176 & 615 \\
\hline & & Dose 8 & 13 & 438 & 170 & 169 & 707 & 9 & 435 & 216 & 130 & 667 \\
\hline
\end{tabular}

Baseline 1 and 2 were taken prior to the administration of study preparation.

Dose 1 = 1 capsule daily for one week; Dose $2=2$ capsules daily for one week;

Dose $3=4$ capsules daily for one week; and Dose $4=8$ capsules daily for one week

\section{Serum ORAC}

The response over doses formed a consistent pattern for female smokers and non-smokers and male non-smokers. Relative to this typical pattern, a number of anomalies were observed in the male smoker data. These data were excluded from further analyses so that models could be focused on estimating the typical response profile.

Two different types of models were fitted to the data. The first treated all effects, group (3 levels - male nonsmoker, female non smoker and female smoker) and dose (5 levels) as factors (effects model). The second fitted dose response models that treated group as a factor but dose as a linear $(0,1,2,4,8)$ component and dose squared $(0,1,4,16,64)$ as a quadratic component. Dose response models always retained linear and quadratic dose effects even if non significant.

Full models were initially fitted and appropriate nonsignificant factors were eliminated. All models were fitted as restricted maximum likelihood mixed models with hierarchical decomposition (Type 1) using covariance structures as specified.
The full factorial model is reported in Table 2 and included all main effects (group and dose) and the group by dose interaction, and the main effects only model for serum ORAC together with degrees of freedom and $p$ values. There was a significant dose effect $(p=0.040)$ for the serum ORAC primary outcome.

Estimated Means and standard errors for dose levels for serum ORAC and p values for Bonferroni adjusted post hoc comparisons with baseline means presented in Table 3 . The predicted means $( \pm$ SE) by dose are presented in Figure 2.

There were significant increases in serum ORAC levels from baseline (mean 376.4) in the dose of 4 capsules per day (mean 514.0) $\mathrm{p} \leq 0.010$, an increase in means of $36.5 \%$. Note that male smokers were not included in these analyses.

\section{ORAC Dose response models}

Progressively fitted models for serum ORAC are reported in Table 4. There was no significant interaction and no significant group effect for the serum ORAC primary 


\section{Smokers}

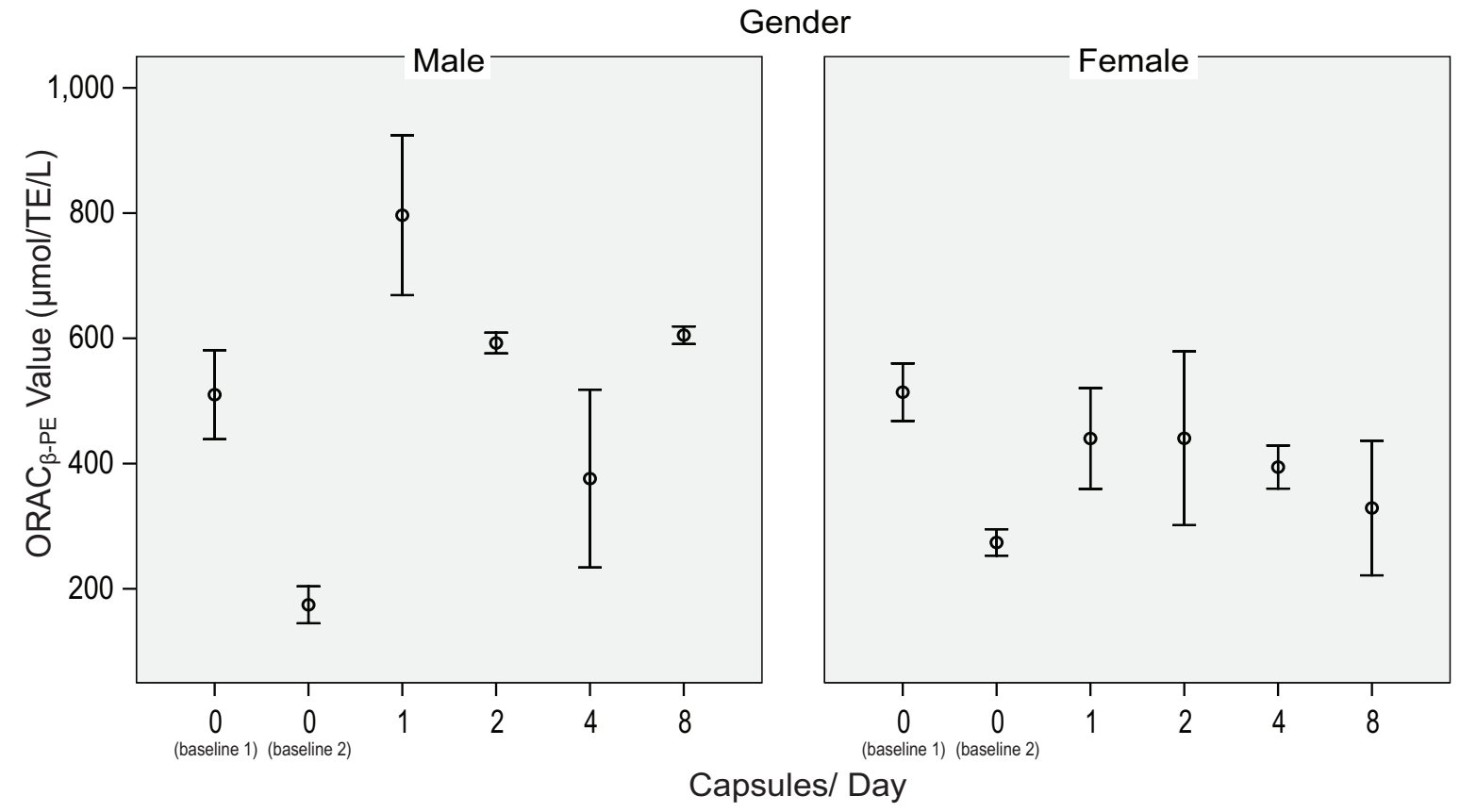

\section{Non-Smokers}

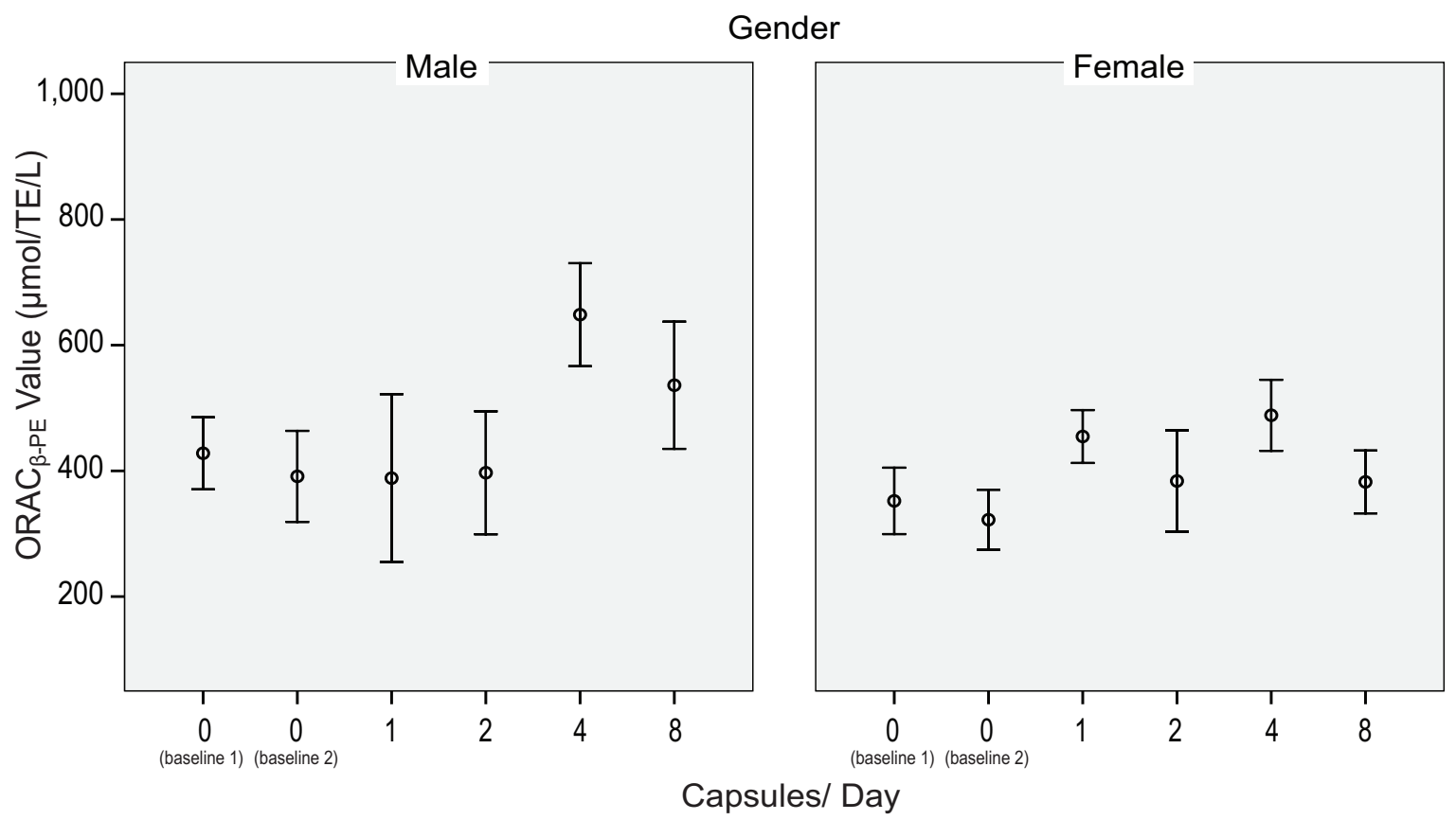

Figure 1 Serum ORAC - Plots of Means $( \pm$ SE) by gender and smoking status for each dose. Baseline 1 and 2 were taken prior to the administration of study preparation. 
Table 2: The effects models for serum ORAC with p values (hierarchical method).

\begin{tabular}{llll}
\hline & & P values & \\
\hline Effect & df & Full Factorial Model & Main Effects Model \\
\hline Intercept & 1 & 0.000 & 0.000 \\
Group & 2 & 0.350 & 0.358 \\
Dose & 4 & $\mathbf{0 . 0 4 3}$ & $\mathbf{0 . 0 4 0}$ \\
Group * dose & 8 & 0.492 & \\
\hline
\end{tabular}

outcome. In the final model (Model 3) with any interactions and the group effect eliminated, the quadratic dose effect was significant $\mathrm{p} \leq 0.047$. The regression parameters results of the final model (Model 3) are reported in Table 5. By differentiating the quadratic equation and equating the derivative to zero, a maximum or minimum dose can be determined. The quadratic equation for serum ORAC is $Y=373.4+46.5 *$ dose $-4.9 *$ dose $*$ dose. Therefore, $d y / d x=46.5-4.9 * 2 * d o s e$. By equating $d y / d x$ $=0$ enables one to solve the equation dose $=-46.5 /(-$ $4.9 * 2)$. Therefore, the optimal estimated dose is 4.7 capsules per day.

\section{Immune Function}

The secondary outcome measures of immune function were 1) mature t cell numbers; 2) mature b cell numbers; 3) helper t cell numbers; 4) suppressant t cell numbers; 5) natural killer cell numbers; 6) phagocytosis of granulocytes; 7) phagocytosis of monocytes; 8) natural killer cell cytotoxicity; and 9) cox 2 expression. Descriptive statistics including sample size, mean, standard deviation, minima and maxima for these outcome measures are reported in Table 6 by dosage level, gender and smoking status.

General linear mixed models (SPSS Mixed) with repeated measures were fitted to the data to ensure maximise retention of data on subjects with missed occasions of measurement. Optimal variance-covariance structures (compound symmetry or completely general or unstructured) were fitted to adjust the estimates and their standard errors for the dependency arising from repeated measurements on the same subjects.
The main effects factorial model (smoker, gender and dose) for all secondary outcome measures together with degrees of freedom and $\mathrm{p}$ values is reported in Table 7. All 2 way and 3 way interactions were non significant. Hierarchical method of fitting was used so that measurements were adjusted for smoking status, and gender before the dose factor was fitted.

The fitting of the factorial models resulted in significant smoking status factor for mature b cell numbers ( $\mathrm{p} \leq$ $0.028)$, natural killer cell numbers ( $\mathrm{p} \leq 0.003$ ) and urinary creatinine ( $\mathrm{p} \leq 0.029)$; significant gender factor for phagocytosis of granulocytes ( $\mathrm{p} \leq 0.035$ ), phagocytosis of monocytes ( $\mathrm{p} \leq 0.007)$ and natural killer cell activity ( $\mathrm{p} \leq$ 0.040 ); and significant dose factor for phagocytosis of granulocytes ( $\mathrm{p} \leq 0.000)$, phagocytosis of monocytes $(\mathrm{p} \leq$ $0.003)$ and cox 2 expression ( $\mathrm{p} \leq 0.001)$.

The assays for phagocytosis of granulocytes and monocytes were handled by a single operator for all measurements excepting week 4. As these measurements are sensitive to laboratory operator variation it was decided by the study team to undertake separate analysis with the dose of 4 capsules per day excluded. Under these conditions there was a significant dose effect retained for phagocytosis of granulocytes only ( $\mathrm{p} \leq 0.000)$.

The significant effects together with estimated marginal means, standard errors and significant post hoc comparisons (Bonferroni adjusted) for secondary outcome variables is reported in Table 8 . The two variables which had a significant dose effect, phagocytosis of granulocytes (with 4 capsule dose excluded) and cox 2 expression are shown in Figure 3.

Table 3: Serum ORAC estimated means ( \pm SE) and $p$ values for post-hoc comparisons (male smokers excluded).

\begin{tabular}{llll}
\hline Dose & Mean & SE & p value for comparison with baseline \\
\hline Baseline & 376.42 & 31.50 & 0.898 \\
1 & 430.15 & 39.79 & 39.79 \\
2 & 395.15 & 39.79 & 1.000 \\
4 & 514.04 & 43.09 & $\mathbf{0 . 0 1 0}$ \\
\hline
\end{tabular}




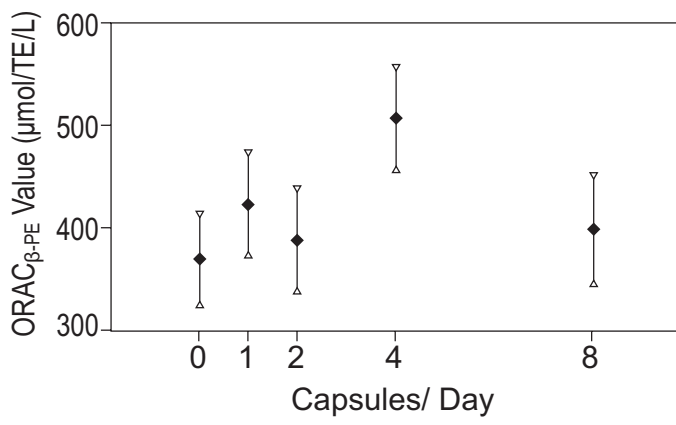

Figure 2 Serum ORAC predicted means $( \pm$ SE) by dose(male smokers excluded).

\section{Safety}

Participants report of adverse events treated with permitted medication (paracetamol/acetaminophen) included, headache $(n=6)$, sports related pain $(n=1)$, and period pain $(\mathrm{n}=-1)$. Three participants reported the following adverse events but did not use medication, removal of basal cell carcinoma from the right cheek $(n=1)$, preparatory injections for overseas travel (hepatitis $\mathrm{A}$ and typhoid) $(\mathrm{n}=1)$, flatulence and constipation $(\mathrm{n}=1)$. One subject (35 year old female) treated a cold sore with Llysine $500 \mathrm{mgs}$ over 4 days during week 4 .

Repeated measures analyses using SPSS GLM was used to analyse the baseline and final scores for safety measures for the full factorial model of smoking status, gender and smoking status by gender interaction. Post-hoc comparisons of baseline measurement versus final measurement for any safety variable showing a significant effect was undertaken. There were some significant changes in the safety variables (full blood count, liver function, urea, creatinine and electrolytes) over the course of the trial but these were generally small, well within clinical reference ranges and assessed as not of clinical significance. These were 1) a decrease in platelet count in all subjects (normal adult reference range: 150$400 \times 10^{9} / \mathrm{L}$ ) from an estimated marginal mean of 272.68 to 250.82 ( $\mathrm{p} \leq 0.005) ; 2$ ) a decrease in serum potassium in all subjects (normal adult reference range: $3.8-4.9 \mathrm{mmol} /$ L) from 4.46 to 4.26 ( $\leq 50.011) ; 3)$ an increase in white cell count in female smokers (normal adult reference range: $4.0-10.0 \times 109 / \mathrm{L})$ from 7.40 to $8.42(\mathrm{p} \leq 0.048)$; and 4) an increase in alkaline phosphatase (ALP) in male nonsmokers (normal adult reference range: $47-136 \mathrm{u} / \mathrm{L}$ ) from 65.60 to $71.80(\mathrm{p} \leq 0.050)$.

A similar analysis was undertaken for vital signs (pulse, systolic and diastolic blood pressure and weight using a main effects factorial model (smoker, gender and dose). Hierarchical method of fitting was used so that measurements were adjusted for smoking status, and gender prior to dose being fitted.

This showed a significant gender factor for systolic blood pressure $(p \leq 0.050)$ and significant dose factor for both weight $(\mathrm{p} \leq 0.003)$ and systolic blood pressure $(\mathrm{p} \leq$ 0.022 ). Mean weight reduction of $0.8 \mathrm{~kg}$ was observed over the 4-week treatment period. The weight reduction was found not to differ significantly between males and females. Similarly a decrease in mean systolic blood pressure (121 down to $117 \mathrm{mmHg}$ ) was also observed. The reduction in systolic blood pressure was also found not to differ significantly between males and females.

\section{Discussion}

A significant increase in antioxidant activity (serum ORAC) was observed between a dose of zero to a dose of 4 capsules per day $(\mathrm{p} \leq 0.040)$. Whilst the observed levels of serum ORAC differed between groups defined in terms of gender and smoking status, the extent of the increase did not differ significantly among these groups $(p \leq 0.492)$. The percentage increase in the serum ORAC mean from baseline to 4 capsules daily was $36.6 \%$. Given the effect was only seen in both genders in non-smokers further investigation needs to be in this cohort.

A quadratic function for dose levels was fitted in order to estimate a dose response curve for estimating the optimal dose. The quadratic component of the curve was significant $(\mathrm{p}=0.047)$, with predicted serum ORAC scores increasing from the zero dose to a maximum at a predicted dose of 4.7 capsules per day and decreasing for

Table 4: Progressively fitted models for serum ORAC with p values (hierarchical method) [male smokers excluded].

\begin{tabular}{lllll}
\hline Effect & df & Model 1 & Model 2 & Model 3 \\
\hline Intercept & 1 & 0.000 & 0.000 & 0.000 \\
Group & 1 & 0.206 & 0.096 & 0.135 \\
Linear dose & 1 & 0.158 & 0.153 & $\mathbf{0 . 0 4 7}$ \\
Quadratic dose & 1 & $\mathbf{0 . 0 4 7}$ & & \\
Linear dose * Group & 1 & 0.210 & & \\
Quadratic dose * Group & 1 & 0.959 & & \\
\hline
\end{tabular}




\begin{tabular}{|c|c|c|c|c|c|c|c|}
\hline \multirow[b]{2}{*}{ Parameter } & \multirow[b]{2}{*}{ Estimate } & \multirow[b]{2}{*}{ SE } & \multirow[b]{2}{*}{ df } & \multirow[b]{2}{*}{$\mathbf{t}$} & \multirow[b]{2}{*}{ Sig. } & \multicolumn{2}{|l|}{$95 \%$ C I } \\
\hline & & & & & & Lower Bound & Upper Bound \\
\hline & & & & & & 316.9 & 429.9 \\
\hline DOSE & 46.54 & 19.71 & 97.2 & 2.36 & 0.020 & 7.4 & 85.7 \\
\hline DOSE_SQ & -4.89 & 2.43 & 97.5 & -2.01 & 0.047 & -9.7 & -0.06 \\
\hline
\end{tabular}

higher doses. This suggests that the optimal dose to assess in a Phase 3 randomized controlled trial is 4 capsules daily.

A few studies have investigated the effects of dietary changes via foods or supplements on serum ORAC. In food studies, increases in serum ORAC have been documented following ingestion of strawberries (14.4\% increase) and spinach (28.5\% increase)[12], buckwheat honey (7\% increase) [13] and concord grape juice ( $8 \%$ increase) [23]. Ingestion of a high-carotenoid content diet had no effect on serum ORAC [24].

The results of dietary supplementation trials on effecting serum antioxidant status have been mixed. In a placebo-controlled trial of healthy adults, a single $100 \mathrm{~g}$ dose of wild blueberry powder significantly increased serum ORAC by up to $16 \%$ [25] and a single $1.25 \mathrm{~g}$ dose of vitamin $C$ raised serum ORAC by $23 \%$ [12]. In a second placebo-controlled study of $500 \mathrm{mg} /$ day vitamin C, serum ORAC was significantly increased, but the percent change was not indicated [26]. Additional studies of supplements designed to have antioxidant benefits have demonstrated no effect on serum ORAC: an antioxidant supplement (vitamin E, beta-carotene, ascorbic acid, selenium, alpha-lipoic acid, $\mathrm{N}$-acetyl 1-cysteine, catechin, lutein, and lycopene) [27]; either of two antioxidant supplements (an antioxidant vitamin/mineral table or a vita$\mathrm{min} / \mathrm{mineral} /$ fruit and vegetable powder capsule) [24]; or a fruit-based antioxidant drink (MonaVie Active, Salt Lake City, Utah) [28]. The Ambrotose AO capsules in this study which increase serum ORAC by $36 \%$ appears to be the most promising antioxidant supplement investigated to date, providing more protection than spinach or high dose vitamin $C$.

Among the secondary outcome measures, a significant dose effect was observed on phagocytosis of granulocytes, with the increase being significant from a zero dose to dose of 8 capsules per day. Due to laboratory operator variation, the data for dose 4 were deemed to be inconsistent with the remaining data and excluded from analysis. It was not possible therefore to determine whether there was a significant increase at a dose of less than 8 capsules per day. This represents a $12 \%$ increase from baseline and suggests that the preparation may have an immunomod- ulatory effect by improving the non-specific, anti-infective mechanisms of defence. The study was not powered for measuring the secondary outcomes which were exploratory in nature and the fact that there was no change in the lymphocyte subset counts or in the other two markers of non-specific immune response, phagocytosis by monocytes or in natural killer cell cytotoxicity may be a type II error and these results, therefore, cannot be considered conclusive.

A significant increase was also observed on Cox 2 expression between a zero dose and a dose of 1 capsule per day, with Cox 2 expression decreasing from this high point at higher doses but remaining above the zero dose level though none of the other comparisons were significant. The inducible form of cyclooxygenase, COX-2, is an immediate-early response gene with complex regulation that plays an essential role in vascular homeostasis and inflammation. Pharmacological manipulation of COX-2 activity can have both beneficial and problematic clinical effects depending on the substrates available in the cell membrane [29], though the increase of $4 \%$ seen in this study is unlikely to be of any clinical significance.

The preparation was demonstrated to be safe over the course of the study. Adverse events experienced during were mild and self limiting, there were no changes in the haemopoietic, liver or renal systems of clinical significance and the vital signs remained healthy. Unanticipated changes in systolic blood pressure and weight moved in a generally beneficial direction but were not of any real clinical significance.

The most significant limitation of this study was that it was open label combined Phase 1 and 2 trial and is subject to potential bias that is reduced with the use of randomization and blinding.

\section{Conclusion}

It is important that this study is not over interpreted; it aimed to find an optimal dose to assess the study medication using a more rigorous clinical trial design. The study achieved this aim and demonstrated that the study medication has the potential to increase antioxidant activity in non-smokers. These activities now need to be demon- 
Table 6: Immune function means ( \pm SD), minima and maxima by dosage level, gender and smoking status.

\begin{tabular}{|c|c|c|c|c|c|c|c|c|c|c|c|c|}
\hline \multirow{2}{*}{$\begin{array}{l}\text { Secondary } \\
\text { Outcome } \\
\text { Measures }\end{array}$} & & & \multicolumn{5}{|c|}{ Non Smoker } & \multicolumn{5}{|c|}{ Smoker } \\
\hline & & & $\mathbf{N}$ & Mean & SD & Min & Max & $\mathbf{N}$ & Mean & SD & Min & Max \\
\hline \multirow{12}{*}{$\begin{array}{l}\text { Mature t cell } \\
\text { Number }\end{array}$} & Male & Baseline 1 & 5 & 1.52 & 0.31 & 1.10 & 1.77 & 3 & 2.18 & 0.62 & 1.74 & 2.62 \\
\hline & & Baseline 2 & 5 & 1.56 & 0.31 & 1.19 & 1.99 & 3 & 1.75 & 0.07 & 1.68 & 1.82 \\
\hline & & Dose 1 & 5 & 1.56 & 0.29 & 1.23 & 1.82 & 3 & 1.97 & 0.28 & 1.69 & 2.25 \\
\hline & & Dose 2 & 5 & 1.50 & 0.40 & 1.12 & 1.99 & 3 & 1.81 & 0.16 & 1.63 & 1.94 \\
\hline & & Dose 4 & 5 & 1.56 & 0.56 & 1.11 & 2.31 & 3 & 1.93 & 0.25 & 1.64 & 2.12 \\
\hline & & Dose 8 & 5 & 1.65 & 0.54 & 1.21 & 2.37 & 3 & 2.20 & 0.39 & 1.84 & 2.62 \\
\hline & Female & Baseline 1 & 8 & 1.56 & 0.46 & 1.00 & 2.17 & 6 & 2.01 & 0.68 & 0.97 & 2.76 \\
\hline & & Baseline 2 & 8 & 1.59 & 0.34 & 1.09 & 1.99 & 6 & 2.01 & 0.70 & 0.95 & 2.98 \\
\hline & & Dose 1 & 8 & 1.56 & 0.29 & 1.07 & 1.93 & 6 & 1.99 & 0.74 & 0.80 & 2.75 \\
\hline & & Dose 2 & 8 & 1.68 & 0.39 & 0.99 & 2.12 & 6 & 1.99 & 0.67 & 0.86 & 2.76 \\
\hline & & Dose 4 & 8 & 1.55 & 0.35 & 0.95 & 1.97 & 6 & 1.99 & 0.77 & 0.89 & 2.97 \\
\hline & & Dose 8 & 8 & 1.63 & 0.46 & 1.02 & 2.26 & 6 & 1.85 & 0.74 & 1.11 & 2.87 \\
\hline \multirow{12}{*}{$\begin{array}{l}\text { Mature } b \text { cell } \\
\text { number }\end{array}$} & Male & Baseline 1 & 5 & 0.24 & 0.08 & 0.17 & 0.36 & 3 & 0.50 & 0.15 & 0.39 & 0.60 \\
\hline & & Baseline 2 & 5 & 0.22 & 0.06 & 0.16 & 0.31 & 3 & 0.37 & 0.16 & 0.26 & 0.55 \\
\hline & & Dose 1 & 5 & 0.25 & 0.10 & 0.14 & 0.36 & 3 & 0.39 & 0.11 & 0.32 & 0.52 \\
\hline & & Dose 2 & 5 & 0.22 & 0.06 & 0.14 & 0.28 & 3 & 0.36 & 0.14 & 0.27 & 0.52 \\
\hline & & Dose 4 & 5 & 0.22 & 0.06 & 0.15 & 0.30 & 3 & 0.36 & 0.15 & 0.27 & 0.53 \\
\hline & & Dose 8 & 5 & 0.22 & 0.05 & 0.19 & 0.30 & 3 & 0.42 & 0.18 & 0.29 & 0.63 \\
\hline & Female & Baseline 1 & 8 & 0.24 & 0.05 & 0.17 & 0.34 & 6 & 0.39 & 0.17 & 0.23 & 0.59 \\
\hline & & Baseline 2 & 8 & 0.24 & 0.05 & 0.16 & 0.29 & 6 & 0.32 & 0.16 & 0.11 & 0.53 \\
\hline & & Dose 1 & 8 & 0.25 & 0.08 & 0.15 & 0.37 & 6 & 0.32 & 0.13 & 0.14 & 0.50 \\
\hline & & Dose 2 & 8 & 0.26 & 0.08 & 0.16 & 0.38 & 6 & 0.33 & 0.14 & 0.17 & 0.54 \\
\hline & & Dose 4 & 8 & 0.24 & 0.06 & 0.15 & 0.34 & 6 & 0.35 & 0.20 & 0.11 & 0.60 \\
\hline & & Dose 8 & 8 & 0.25 & 0.05 & 0.18 & 0.30 & 6 & 0.34 & 0.17 & 0.12 & 0.49 \\
\hline
\end{tabular}


Table 6: Immune function means ( \pm SD), minima and maxima by dosage level, gender and smoking status. (Continued)

\begin{tabular}{|c|c|c|c|c|c|c|c|c|c|c|c|c|}
\hline \multirow{12}{*}{$\begin{array}{l}\text { Helper t cell } \\
\text { number }\end{array}$} & Male & Baseline 1 & 5 & 0.99 & 0.30 & 0.58 & 1.23 & 3 & 1.27 & 0.18 & 1.14 & 1.40 \\
\hline & & Baseline 2 & 5 & 0.98 & 0.31 & 0.69 & 1.40 & 3 & 1.19 & 0.31 & 0.88 & 1.50 \\
\hline & & Dose 1 & 5 & 1.01 & 0.31 & 0.59 & 1.28 & 3 & 1.32 & 0.23 & 1.13 & 1.58 \\
\hline & & Dose 2 & 5 & 0.99 & 0.39 & 0.63 & 1.43 & 3 & 1.21 & 0.28 & 0.99 & 1.53 \\
\hline & & Dose 4 & 5 & 1.02 & 0.47 & 0.58 & 1.61 & 3 & 1.29 & 0.37 & 1.06 & 1.71 \\
\hline & & Dose 8 & 5 & 1.09 & 0.52 & 0.64 & 1.76 & 3 & 1.53 & 0.53 & 1.22 & 2.14 \\
\hline & Female & Baseline 1 & 8 & 0.96 & 0.29 & 0.70 & 1.46 & 6 & 1.24 & 0.39 & 0.60 & 1.61 \\
\hline & & Baseline 2 & 8 & 1.00 & 0.22 & 0.73 & 1.29 & 6 & 1.24 & 0.38 & 0.61 & 1.59 \\
\hline & & Dose 1 & 8 & 0.97 & 0.15 & 0.73 & 1.20 & 6 & 1.24 & 0.46 & 0.52 & 1.83 \\
\hline & & Dose 2 & 8 & 1.06 & 0.23 & 0.66 & 1.33 & 6 & 1.23 & 0.39 & 0.56 & 1.75 \\
\hline & & Dose 4 & 8 & 0.98 & 0.21 & 0.62 & 1.18 & 6 & 1.25 & 0.49 & 0.59 & 2.06 \\
\hline & & Dose 8 & 8 & 1.02 & 0.27 & 0.61 & 1.29 & 6 & 1.10 & 0.29 & 0.75 & 1.44 \\
\hline \multirow{12}{*}{$\begin{array}{l}\text { Suppressant t } \\
\text { cell number }\end{array}$} & Male & Baseline 1 & 5 & 0.47 & 0.12 & 0.28 & 0.59 & 3 & 0.77 & 0.54 & 0.39 & 1.15 \\
\hline & & Baseline 2 & 5 & 0.54 & 0.19 & 0.28 & 0.81 & 3 & 0.54 & 0.25 & 0.38 & 0.83 \\
\hline & & Dose 1 & 5 & 0.51 & 0.17 & 0.27 & 0.75 & 3 & 0.61 & 0.31 & 0.42 & 0.96 \\
\hline & & Dose 2 & 5 & 0.50 & 0.17 & 0.31 & 0.70 & 3 & 0.55 & 0.23 & 0.37 & 0.81 \\
\hline & & Dose 4 & 5 & 0.52 & 0.19 & 0.29 & 0.72 & 3 & 0.59 & 0.26 & 0.43 & 0.89 \\
\hline & & Dose 8 & 5 & 0.53 & 0.17 & 0.31 & 0.66 & 3 & 0.63 & 0.18 & 0.49 & 0.84 \\
\hline & Female & Baseline 1 & 8 & 0.55 & 0.20 & 0.30 & 0.89 & 6 & 0.77 & 0.43 & 0.36 & 1.50 \\
\hline & & Baseline 2 & 8 & 0.53 & 0.16 & 0.31 & 0.80 & 6 & 0.74 & 0.45 & 0.33 & 1.62 \\
\hline & & Dose 1 & 8 & 0.54 & 0.15 & 0.34 & 0.79 & 6 & 0.72 & 0.42 & 0.27 & 1.50 \\
\hline & & Dose 2 & 8 & 0.55 & 0.19 & 0.30 & 0.86 & 6 & 0.72 & 0.42 & 0.29 & 1.51 \\
\hline & & Dose 4 & 8 & 0.53 & 0.16 & 0.32 & 0.81 & 6 & 0.73 & 0.41 & 0.29 & 1.45 \\
\hline & & Dose 8 & 8 & 0.56 & 0.24 & 0.31 & 0.98 & 6 & 0.77 & 0.54 & 0.33 & 1.55 \\
\hline \multirow{4}{*}{$\begin{array}{l}\text { Natural killer } \\
\text { cell number }\end{array}$} & Male & Baseline 1 & 5 & 0.20 & 0.14 & 0.08 & 0.44 & 3 & 0.36 & 0.02 & 0.34 & 0.37 \\
\hline & & Baseline 2 & 5 & 0.22 & 0.16 & 0.12 & 0.50 & 3 & 0.27 & 0.04 & 0.24 & 0.31 \\
\hline & & Dose 1 & 5 & 0.19 & 0.13 & 0.11 & 0.41 & 3 & 0.29 & 0.02 & 0.28 & 0.32 \\
\hline & & Dose 2 & 5 & 0.13 & 0.04 & 0.09 & 0.17 & 3 & 0.29 & 0.03 & 0.26 & 0.31 \\
\hline
\end{tabular}


Table 6: Immune function means ( \pm SD), minima and maxima by dosage level, gender and smoking status. (Continued)

\begin{tabular}{|c|c|c|c|c|c|c|c|c|c|c|c|c|}
\hline & & Dose 4 & 5 & 0.16 & 0.06 & 0.10 & 0.21 & 3 & 0.30 & 0.03 & 0.27 & 0.32 \\
\hline & & Dose 8 & 5 & 0.17 & 0.08 & 0.07 & 0.24 & 3 & 0.34 & 0.12 & 0.26 & 0.48 \\
\hline & \multirow[t]{6}{*}{ Female } & Baseline 1 & 8 & 0.18 & 0.08 & 0.10 & 0.32 & 6 & 0.21 & 0.12 & 0.12 & 0.41 \\
\hline & & Baseline 2 & 8 & 0.18 & 0.06 & 0.10 & 0.28 & 6 & 0.25 & 0.15 & 0.10 & 0.50 \\
\hline & & Dose 1 & 8 & 0.19 & 0.08 & 0.10 & 0.35 & 6 & 0.21 & 0.09 & 0.12 & 0.37 \\
\hline & & Dose 2 & 8 & 0.20 & 0.07 & 0.11 & 0.29 & 6 & 0.24 & 0.12 & 0.11 & 0.45 \\
\hline & & Dose 4 & 8 & 0.17 & 0.06 & 0.10 & 0.26 & 6 & 0.25 & 0.09 & 0.14 & 0.37 \\
\hline & & Dose 8 & 8 & 0.18 & 0.09 & 0.09 & 0.31 & 6 & 0.32 & 0.18 & 0.14 & 0.56 \\
\hline \multirow{12}{*}{$\begin{array}{l}\text { Phagocytosis } \\
\text { of } \\
\text { Granulocytes }\end{array}$} & Male & Baseline 1 & 5 & 37.1 & 6.0 & 31.0 & 44.4 & 3 & 40.6 & 1.3 & 39.6 & 41.5 \\
\hline & & Baseline 2 & 5 & 47.6 & 5.1 & 39.6 & 53.2 & 3 & 40.4 & 8.4 & 31.0 & 47.2 \\
\hline & & Dose 1 & 5 & 35.4 & 3.1 & 33.0 & 39.8 & 3 & 48.0 & 4.9 & 42.4 & 51.6 \\
\hline & & Dose 2 & 5 & 48.8 & 14.3 & 27.5 & 58.1 & 3 & 49.2 & 15.0 & 32.8 & 62.2 \\
\hline & & Dose 4 & 5 & 40.4 & 6.3 & 30.9 & 44.5 & 3 & 38.6 & 3.0 & 35.2 & 40.6 \\
\hline & & Dose 8 & 5 & 48.6 & 3.4 & 44.5 & 51.5 & 3 & 48.1 & 5.5 & 43.7 & 54.2 \\
\hline & Female & Baseline 1 & 8 & 38.8 & 10.1 & 27.6 & 57.3 & 6 & 40.0 & 8.8 & 27.1 & 49.3 \\
\hline & & Baseline 2 & 8 & 51.4 & 7.4 & 37.6 & 60.7 & 6 & 53.8 & 8.0 & 46.0 & 65.2 \\
\hline & & Dose 1 & 8 & 49.3 & 13.3 & 33.3 & 75.7 & 6 & 46.3 & 9.0 & 32.9 & 57.9 \\
\hline & & Dose 2 & 8 & 46.0 & 13.9 & 26.6 & 64.2 & 6 & 51.4 & 13.8 & 28.6 & 65.9 \\
\hline & & Dose 4 & 8 & 39.5 & 7.3 & 34.8 & 51.7 & 6 & 48.5 & 8.8 & 36.2 & 58.6 \\
\hline & & Dose 8 & 8 & 50.9 & 8.9 & 39.5 & 63.7 & 6 & 56.3 & 6.7 & 47.0 & 61.9 \\
\hline \multirow{9}{*}{$\begin{array}{l}\text { Phagocytosis } \\
\text { of monocytes }\end{array}$} & Male & Baseline 1 & 5 & 31.1 & 4.5 & 24.9 & 35.6 & 3 & 29.1 & 3.5 & 26.6 & 31.5 \\
\hline & & Baseline 2 & 5 & 35.5 & 2.2 & 33.3 & 38.9 & 3 & 30.4 & 9.4 & 23.9 & 41.2 \\
\hline & & Dose 1 & 5 & 27.1 & 3.2 & 23.5 & 32.0 & 3 & 35.3 & 3.1 & 31.9 & 38.0 \\
\hline & & Dose 2 & 5 & 38.4 & 10.8 & 22.5 & 45.7 & 3 & 35.4 & 10.1 & 25.8 & 46.0 \\
\hline & & Dose 4 & 5 & 31.8 & 5.7 & 25.1 & 37.6 & 3 & 27.4 & 1.4 & 25.8 & 28.3 \\
\hline & & Dose 8 & 5 & 37.6 & 1.8 & 35.8 & 39.7 & 3 & 32.4 & 5.4 & 26.5 & 37.2 \\
\hline & Female & Baseline 1 & 8 & 34.7 & 8.4 & 20.0 & 47.3 & 6 & 32.4 & 5.1 & 25.3 & 39.2 \\
\hline & & Baseline 2 & 8 & 39.5 & 7.7 & 28.9 & 47.7 & 6 & 39.3 & 5.4 & 30.3 & 45.1 \\
\hline & & Dose 1 & 8 & 35.5 & 8.1 & 26.0 & 49.0 & 6 & 34.6 & 6.5 & 24.8 & 42.6 \\
\hline
\end{tabular}


Table 6: Immune function means ( \pm SD), minima and maxima by dosage level, gender and smoking status. (Continued)

\begin{tabular}{|c|c|c|c|c|c|c|c|c|c|c|c|c|}
\hline & & Dose 2 & 8 & 33.1 & 7.3 & 22.5 & 45.3 & 6 & 33.8 & 9.5 & 21.5 & 49.8 \\
\hline & & Dose 4 & 8 & 30.9 & 4.6 & 25.0 & 38.6 & 6 & 36.2 & 7.5 & 30.5 & 49.8 \\
\hline & & Dose 8 & 8 & 32.5 & 5.5 & 24.0 & 39.9 & 6 & 34.5 & 8.8 & 24.4 & 44.8 \\
\hline \multirow{12}{*}{$\begin{array}{l}\text { Natural killer } \\
\text { cell } \\
\text { cytotoxicity }\end{array}$} & Male & Baseline 1 & 5 & 15.5 & 6.0 & 10.6 & 25.2 & 3 & 22.0 & 0.9 & 21.3 & 22.6 \\
\hline & & Baseline 2 & 5 & 18.7 & 5.4 & 11.0 & 25.4 & 3 & 22.8 & 17.0 & 10.7 & 34.8 \\
\hline & & Dose 1 & 5 & 18.1 & 6.8 & 10.4 & 24.8 & 3 & 22.4 & 4.5 & 17.6 & 26.5 \\
\hline & & Dose 2 & 5 & 13.7 & 4.8 & 7.5 & 19.3 & 3 & 21.8 & 3.9 & 17.3 & 24.7 \\
\hline & & Dose 4 & 5 & 14.1 & 4.1 & 8.9 & 19.0 & 3 & 23.5 & 6.6 & 17.6 & 30.6 \\
\hline & & Dose 8 & 5 & 15.1 & 2.8 & 11.3 & 17.8 & 3 & 23.2 & 6.0 & 19.6 & 30.1 \\
\hline & Female & Baseline 1 & 8 & 14.8 & 5.9 & 9.1 & 24.0 & 6 & 15.1 & 4.5 & 10.6 & 21.5 \\
\hline & & Baseline 2 & 8 & 13.9 & 5.7 & 8.7 & 25.6 & 6 & 16.5 & 6.6 & 8.6 & 23.4 \\
\hline & & Dose 1 & 8 & 15.0 & 5.3 & 8.9 & 24.6 & 6 & 16.4 & 4.9 & 10.4 & 23.9 \\
\hline & & Dose 2 & 8 & 14.1 & 5.2 & 8.6 & 21.6 & 6 & 16.6 & 4.5 & 10.0 & 20.8 \\
\hline & & Dose 4 & 8 & 13.4 & 4.3 & 7.6 & 19.1 & 6 & 13.3 & 5.5 & 4.1 & 19.3 \\
\hline & & Dose 8 & 8 & 12.5 & 5.0 & 7.8 & 19.1 & 6 & 15.9 & 7.5 & 10.5 & 26.5 \\
\hline \multirow[t]{12}{*}{$\operatorname{Cox} 2$} & Male & Baseline 1 & 5 & 78.0 & 8.9 & 67.8 & 89.6 & 3 & 83.6 & 3.9 & 80.8 & 86.3 \\
\hline & & Baseline 2 & 5 & 82.9 & 2.9 & 79.7 & 85.3 & 3 & 83.0 & 2.2 & 80.6 & 85.0 \\
\hline & & Dose 1 & 5 & 82.6 & 3.1 & 79.0 & 86.4 & 3 & 85.1 & 4.1 & 82.5 & 89.9 \\
\hline & & Dose 2 & 5 & 83.2 & 1.4 & 82.2 & 85.3 & 3 & 79.6 & 2.2 & 78.1 & 82.1 \\
\hline & & Dose 4 & 5 & 78.2 & 5.1 & 73.8 & 85.2 & 3 & 84.8 & 5.0 & 80.9 & 90.5 \\
\hline & & Dose 8 & 5 & 79.4 & 3.6 & 75.4 & 83.5 & 3 & 85.8 & 8.5 & 76.2 & 92.5 \\
\hline & Female & Baseline 1 & 8 & 78.9 & 5.9 & 71.8 & 87.9 & 6 & 80.2 & 5.4 & 76.3 & 89.4 \\
\hline & & Baseline 2 & 8 & 81.0 & 5.5 & 72.0 & 88.5 & 6 & 79.2 & 9.1 & 61.9 & 85.8 \\
\hline & & Dose 1 & 8 & 82.6 & 3.5 & 75.9 & 88.0 & 6 & 85.9 & 3.0 & 82.7 & 90.3 \\
\hline & & Dose 2 & 8 & 83.6 & 3.8 & 77.3 & 89.2 & 6 & 81.3 & 4.0 & 74.8 & 86.0 \\
\hline & & Dose 4 & 8 & 81.0 & 4.3 & 73.4 & 85.2 & 6 & 83.7 & 4.8 & 78.4 & 92.3 \\
\hline & & Dose 8 & 8 & 81.3 & 5.2 & 76.1 & 90.1 & 6 & 82.7 & 5.5 & 76.9 & 87.6 \\
\hline
\end{tabular}

Baseline 1 and 2 were taken prior to the administration of study preparation. 
Table 7: Immune Function p values for the main effects factorial models.

\begin{tabular}{llll}
\hline Secondary Outcome Measures & Smoking status & Gender & Dose \\
\hline Mature t cell number & 0.053 & 0.901 & 0.320 \\
Mature b cell number & $\mathbf{0 . 0 2 9}$ & 0.704 & 0.839 \\
Helper t cell number * & 0.093 & 0.824 & 0.134 \\
Suppressant t cell number & 0.188 & 0.565 & 0.806 \\
Natural killer cell number* & $\mathbf{0 . 0 0 4}$ & 0.165 & 0.179 \\
Phagocytosis of granulocytes* & 0.389 & $\mathbf{0 . 0 3 6}$ & $\mathbf{0 . 0 0 0}$ \\
$\quad$ (4 capsule dose excluded) & 0.607 & $\mathbf{0 . 0 3 8}$ & $\mathbf{0 . 0 0 0}$ \\
Phagocytosis of monocytes * & 0.872 & $\mathbf{0 . 0 0 7}$ & $\mathbf{0 . 0 0 3}$ \\
$\quad$ (4 capsule dose excluded) & 0.516 & $\mathbf{0 . 0 2 0}$ & 0.094 \\
Natural killer cell activity & 0.129 & $\mathbf{0 . 0 4 0}$ & 0.345 \\
Cox 2 inhibition * & 0.937 & 0.630 & $\mathbf{0 . 0 0 1}$ \\
\hline
\end{tabular}

* indicates models were fitted with unstructured variance-covariance otherwise compound symmetry models were fitted.

Table 8: Immune Function significant effects exist and significant post hoc comparisons.

\begin{tabular}{|c|c|c|c|c|c|c|}
\hline Secondary Outcome Measure & Effect & & Mean & SE & Pairwise & p value \\
\hline \multirow[t]{2}{*}{ Mature B Cell Number } & Smoker & No & 0.25 & 0.03 & & 0.028 \\
\hline & & Yes & 0.35 & 0.04 & & \\
\hline \multirow[t]{2}{*}{ Natural Killer Cell Number } & Smoker & No & 0.20 & 0.02 & & 0.003 \\
\hline & & Yes & 0.27 & 0.02 & & \\
\hline \multirow[t]{7}{*}{ Phagocytosis of Granulocytes } & Dose & Baseline & 45.01 & 1.43 & base vs 8 & 0.002 \\
\hline & & 1 & 43.70 & 2.17 & 1 vs 8 & 0.038 \\
\hline & & 2 & 50.68 & 2.89 & 2 vs 4 & 0.010 \\
\hline & & 4 & 42.81 & 1.65 & 4 vs 8 & 0.000 \\
\hline & & 8 & 50.49 & 1.58 & & \\
\hline & Gender & Male & 43.70 & 2.18 & & 0.038 \\
\hline & & Female & 49.37 & 1.73 & & \\
\hline Phagocytosis of Granulocytes & Dose & Baseline & 45.01 & 1.44 & base vs 8 & 0.001 \\
\hline \multirow[t]{5}{*}{ (4 capsule dose excluded) } & & 1 & 43.96 & 2.19 & 1 vs 8 & 0.026 \\
\hline & & 2 & 50.36 & 2.92 & & \\
\hline & & 8 & 50.47 & 1.54 & & \\
\hline & Gender & Male & 44.64 & 2.23 & & 0.035 \\
\hline & & Female & 50.27 & 1.78 & & \\
\hline \multirow[t]{5}{*}{ Phagocytosis of Monocytes } & Dose & Baseline & 34.37 & 0.89 & 2 vs 4 & 0.003 \\
\hline & & 1 & 33.24 & 1.38 & & \\
\hline & & 2 & 35.76 & 1.83 & & \\
\hline & & 4 & 32.01 & 1.27 & & \\
\hline & & 8 & 32.70 & 1.41 & & \\
\hline
\end{tabular}


Table 8: Immune Function significant effects exist and significant post hoc comparisons. (Continued)

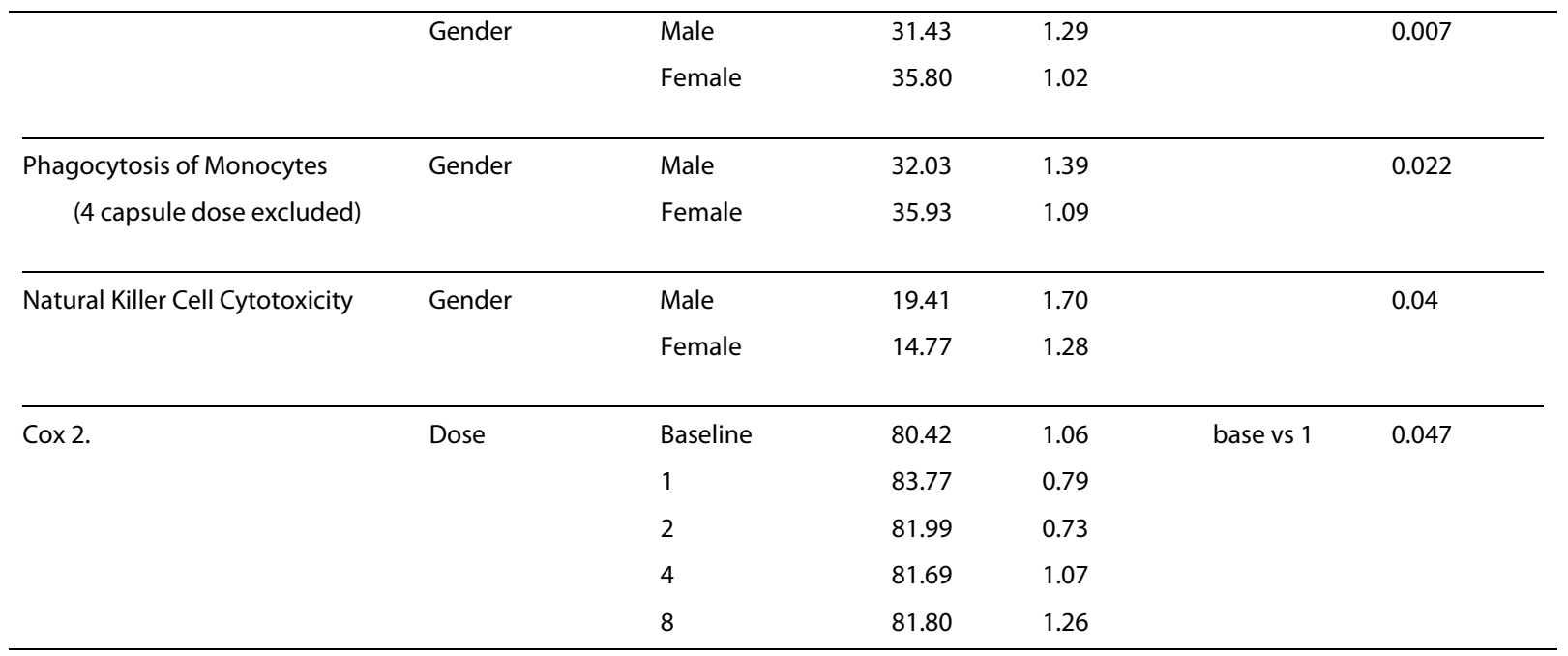
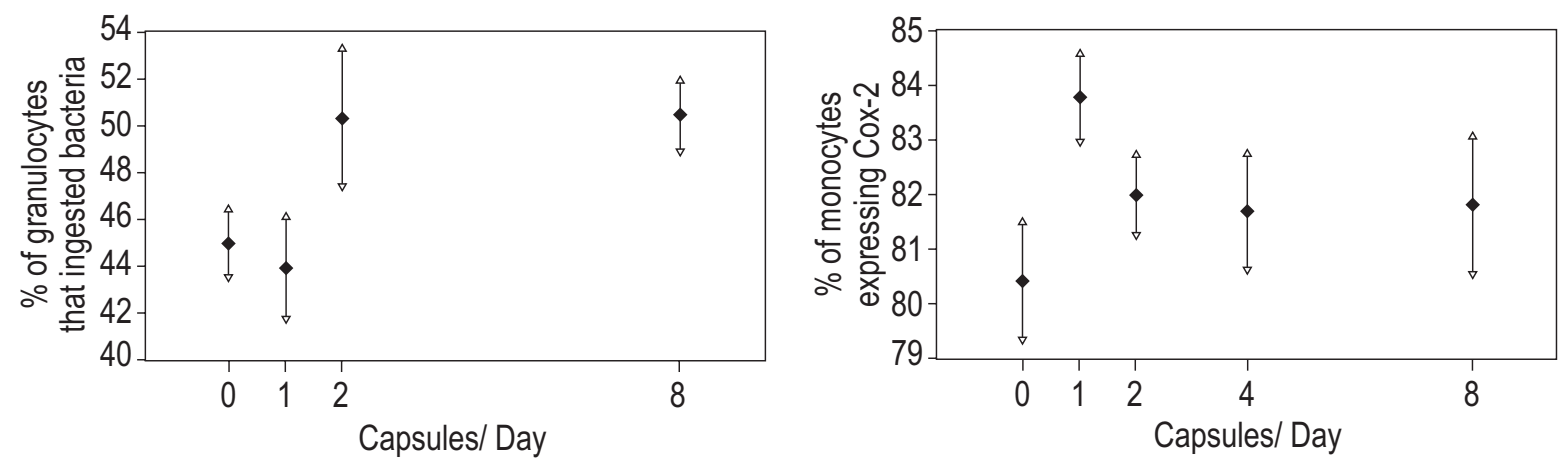

Figure 3 Immune function variables with a significant dose effect.

strated in a Phase 3 randomised double-blind placebocontrolled trial in non-smokers (RCT).

\section{Competing interests}

The study was sponsored by Mannatech Inc (USA) under contract to Southern Cross University and performed independently by NatMed-Research. Mannatech Inc (USA) paid the article-processing charge associated with the publication of this paper.

\section{Authors' contributions}

SPM was the principal investigator and was involved in the study design, management of the clinical trial, interpretation of the results and preparation of the manuscript; LS supervised the laboratory measurements, was involved in study design and interpretation of results and contributed to the manuscript; PAC was involved in study design and interpretation of results and contributed to the manuscript; JO was the study co-ordinator and was involved in the study design, the day to day management of the clinical trial, data entry and contributed to the manuscript; LB supervised the statistical analysis and was involved in the interpretation of the results and contributed to the manuscript; MR undertook the statistical analysis and was involved in the interpretation of the results and contributed to the manuscript; PC undertook the immune function studies and was involved in interpretation of the results and contributed to the manuscript; and CM directs the laboratory where the immune studies and serum ORAC was undertaken and contributed to the manuscript. All authors read and approved the final manuscript.

\section{Acknowledgements}

We thank Don Baker (NatMed-Research) who provided clinical research assistance; Dion Thompson (Centre for Phytochemistry \& Pharmacology) who undertook the antioxidant testing; the Northern Rivers Pathology Unit who undertook the safety measurements; and the participants who made it possible.

\section{Author Details}

'Australian Centre for Complementary Medicine Education and Research, A Joint Venture of the University of Queensland and Southern Cross University, Lismore, Australia, ${ }^{2}$ NatMed-Research Unit, Research Cluster for Health and Wellbeing, Southern Cross University, Lismore, Australia, ${ }^{3}$ Graduate Research College, Southern Cross University, Lismore, Australia, ${ }^{4}$ Centre for Phytochemistry and Pharmacology, Southern Cross University, Lismore, Australia and ${ }^{5}$ The New Zealand Institute for Plant and Food Research Limited, Auckland, New Zealand

Received: 28 March 2009 Accepted: 30 April 2010

Published: 30 April 2010 


\section{References}

1. Conner EM, Grisham MB: Inflammation, free radicals, and antioxidants. Nutrition 1996, 12(4):274-277.

2. Cuzzocrea S, Riley DP, Caputi AP, Salvemini D: Antioxidant therapy: a new pharmacological approach in shock, inflammation, and ischemia/ reperfusion injury. Pharmacol Rev 2001, 53(1):135-159.

3. Kapoor M, Clarkson AN, Sutherland BA, Appleton I: The role of antioxidants in models of inflammation: emphasis on L-arginine and arachidonic acid metabolism. Inflammopharmacology 2005, 12(56):505-519

4. Alonso de Vega JM, Diaz J, Serrano E, Carbonell LF: Plasma redox status relates to severity in critically ill patients. Crit Care Med 2000, 28(6):1812-1814.

5. Motoyama T, Okamoto K, Kukita I, Hamaguchi M, Kinoshita Y, Ogawa H: Possible role of increased oxidant stress in multiple organ failure after systemic inflammatory response syndrome. Crit Care Med 2003, 31(4):1048-1052.

6. Berger MM, Shenkin A: Update on clinical micronutrient supplementation studies in the critically ill. Curr Opin Clin Nutr Metab Care 2006, 9(6):711-716.

7. Berger MM, Chiolero RL: Antioxidant supplementation in sepsis and systemic inflammatory response syndrome. Crit Care Med 2007, 35(9 Suppl):S584-590.

8. Rezaie A, Parker RD, Abdollahi M: Oxidative stress and pathogenesis of inflammatory bowel disease: an epiphenomenon or the cause? Dig Dis Sci 2007, 52(9):2015-2021.

9. Rahimi R, Nikfar S, Larijani B, Abdollahi M: A review on the role of antioxidants in the management of diabetes and its complications. Biomed Pharmacother 2005, 59(7):365-373.

10. Berger MM, Soguel L, Shenkin A, Revelly JP, Pinget C, Baines M, Chiolero $\mathrm{RL}$ : Influence of early antioxidant supplements on clinical evolution and organ function in critically ill cardiac surgery, major trauma, and subarachnoid hemorrhage patients. Crit Care 2008, 12(4):R101.

11. Bhardwaj P, Garg PK, Maulik SK, Saraya A, Tandon RK, Acharya SK: A Randomized Controlled Trial of Antioxidant Supplementation for Pain Relief in Patients with Chronic Pancreatitis. Gastroenterology 2008, 136(1):149-59. e2

12. Cao G, Russell RM, Lischner N, Prior RL: Serum antioxidant capacity is increased by consumption of strawberries, spinach, red wine or vitamin C in elderly women. J Nutr 1998, 128(12):2383-2390.

13. Gheldof N, Wang XH, Engeseth NJ: Buckwheat honey increases serum antioxidant capacity in humans. J Agric Food Chem 2003, 51(5):1500-1505.

14. Azadbakht L, Kimiagar M, Mehrabi Y, Esmaillzadeh A, Hu FB, Willett WC: Dietary soya intake alters plasma antioxidant status and lipid peroxidation in postmenopausal women with the metabolic syndrome. Br J Nutr 2007, 98(4):807-813.

15. Kocyigit A, Koylu AA, Keles $\mathrm{H}$ : Effects of pistachio nuts consumption on plasma lipid profile and oxidative status in healthy volunteers. Nutr Metab Cardiovasc Dis 2006, 16(3):202-209.

16. Jenkins DJ, Kendall CW, Marchie A, Parker TL, Connelly PW, Qian W, Haight JS, Faulkner D, Vidgen E, Lapsley KG, et al:: Dose response of almonds on coronary heart disease risk factors: blood lipids, oxidized low-density lipoproteins, lipoprotein(a), homocysteine, and pulmonary nitric oxide: a randomized, controlled, crossover trial. Circulation 2002, 106(11):1327-1332

17. Durak I, Koksal I, Kacmaz M, Buyukkocak S, Cimen BM, Ozturk HS: Hazelnut supplementation enhances plasma antioxidant potential and lowers plasma cholesterol levels. Clin Chim Acta 1999, 284(1):113-115.

18. Prior RL, Cao G: Analysis of botanicals and dietary supplements for antioxidant capacity: a review. JAOAC Int 2000, 83(4):950-956.

19. Williamson G, Manach C: Bioavailability and bioefficacy of polyphenols in humans. II. Review of 93 intervention studies. Am J Clin Nutr 2005, 81(1 Suppl):243S-255S.

20. Aron PM, Kennedy JA: Flavan-3-ols: nature, occurrence and biological activity. Mol Nutr Food Res 2008, 52(1):79-104.

21. Prior RL, Hoang H, Gu L, Wu X, Bacchiocca M, Howard L, Hampsch-Woodill $M$, Huang D, Ou B, Jacob R: Assays for hydrophilic and lipophilic antioxidant capacity (oxygen radical absorbance capacity (ORAC(FL)) of plasma and other biological and food samples. J Agric Food Chem 2003, 51(11):3273-3279.
22. Ruitenberg JJ, Waters CA: A rapid flow cytometric method for the detection of intracellular cyclooxygenases in human whole blood monocytes and a COX-2 inducible human cell line. $\mathrm{J} /$ mmunol Methods 2003, 274(1-2):93-104

23. O'Byrne DJ, Devaraj S, Grundy SM, Jialal I: Comparison of the antioxidant effects of Concord grape juice flavonoids alpha-tocopherol on markers of oxidative stress in healthy adults. Am J Clin Nutr 2002, 76(6):1367-1374.

24. Nelson JL, Bernstein PS, Schmidt MC, Von Tress MS, Askew EW: Dietary modification and moderate antioxidant supplementation differentially affect serum carotenoids, antioxidant levels and markers of oxidative stress in older humans. J Nutr 2003, 133(10):3117-3123.

25. Kay CD, Holub BJ: The effect of wild blueberry (Vaccinium angustifolium) consumption on postprandial serum antioxidant status in human subjects. Br J Nutr 2002, 88(4):389-398.

26. Huang HY, Appel LJ, Croft KD, Miller ER, Mori TA, Puddey IB: Effects of vitamin $C$ and vitamin $E$ on in vivo lipid peroxidation: results of a randomized controlled trial. Am J Clin Nutr 2002, 76(3):549-555.

27. Schmidt MC, Askew EW, Roberts DE, Prior RL, Ensign WY Jr, Hesslink RE Jr: Oxidative stress in humans training in a cold, moderate altitude environment and their response to a phytochemical antioxidant supplement. Wilderness Environ Med 2002, 13(2):94-105.

28. Jensen GS, Wu X, Patterson KM, Barnes J, Carter SG, Scherwitz L, Beaman R, Endres JR, Schauss AG: In vitro and in vivo antioxidant and antiinflammatory capacities of an antioxidant-rich fruit and berry juice blend. Results of a pilot and randomized, double-blinded, placebocontrolled, crossover study. J Agric Food Chem 2008, 56(18):8326-8333.

29. FitzGerald GA: COX-2 and beyond: Approaches to prostaglandin inhibition in human disease. Nat Rev Drug Discov 2003, 2(11):879-890.

Pre-publication history

The pre-publication history for this paper can be accessed here: http://www.biomedcentral.com/1472-6882/10/16/prepub

doi: $10.1186 / 1472-6882-10-16$

Cite this article as: Myers et al., A forced titration study of the antioxidant and immunomodulatory effects of Ambrotose AO supplement BMC Complementary and Alternative Medicine 2010, 10:16

\section{Submit your next manuscript to BioMed Central and take full advantage of:}

- Convenient online submission

- Thorough peer review

- No space constraints or color figure charges

- Immediate publication on acceptance

- Inclusion in PubMed, CAS, Scopus and Google Scholar

- Research which is freely available for redistribution 